\title{
Formação e atuação da rede de comissários do Santo Ofício em Minas colonial ${ }^{1}$
}

\author{
The making and the actions of the Holy Inquisition \\ Commissioners' network in Colonial Minas Gerais
}

Aldair Carlos Rodrigues*

\section{Resumo}

Focalizando a atuação dos agentes inquisitoriais, este artigo busca esclarecer como a Inquisição portuguesa se relacionou com a estrutura eclesiástica de Minas colonial. A análise se concentra na formação e na atuação da rede de comissários do Santo Ofício na Capitania do ouro. Qual era o perfil desses agentes? Como eles eram recrutados entre a hierarquia eclesiástica local? Que papel eles desempenhavam na ação inquisitorial ocorrida na capitania mineradora? De que forma atuavam? Qual a relação entre a inserção dos comissários nas estruturas eclesiásticas locais e as atividades inquisitoriais desempenhadas por esses agentes?

Palavras-chave: Inquisição portuguesa; Minas colonial; agentes inquisitoriais.

\begin{abstract}
Through the study of the action of the inquisition commissioners, this article seeks to reveal the relations between the Portuguese Inquisition and the ecclesiastical structure of the Minas Gerais State Captaincy in the colonial period. The focus of the analysis will be the making and the action of the network of Holy Inquisition commissioners in the gold Captaincy. What was the profile of these commissioners? How were they recruited from the local ecclesiastical hierarchy? What was the role assigned to them in the inquisitional action that took place in Minas Gerais? How did they act? What was the relationship between the introduction of the commissioners into the local ecclesiastical structures and the commissioners' inquisitorial activities?

Keywords: Portuguese Inquisition; Colonial Minas; Inquisitorial officials.
\end{abstract}

\footnotetext{
* Historiador (UFOP), Mestre e doutorando em História Social (FFLCH/USP), bolsista da Fundação de Amparo à Pesquisa do Estado de São Paulo (Fapesp) - Av. Prof. Mello Moraes, 1235, Bloco C, ap. 602 - Butantã. 05508-030 São Paulo - SP - Brasil. aldairr@yahoo.com.br.
} 


\section{A AtuaÇão InQuisitorial em Minas: CONTEXTo}

Diferentemente do que ocorrera nas colônias espanholas, no Brasil não existiu uma sede do Tribunal do Santo Ofício, apesar da malograda tentativa do seu estabelecimento no período filipino. Com efeito, a Colônia ficou sob a égide da Inquisição de Lisboa, que exercia jurisdição também sobre outras partes do Império luso: as Ilhas Atlânticas, Norte e porção ocidental da África. O único Tribunal instalado no Ultramar português foi o de Goa. ${ }^{2}$

Apesar de nunca ter tido uma sede na Colônia, a Inquisição portuguesa agiu aqui por meio de diversas estratégias, que variaram no tempo e no espaço. As visitações, a colaboração dos bispos e das ordens regulares (sobretudo a Companhia de Jesus), a justiça eclesiástica e uma rede de agentes, composta principalmente por comissários e familiares, foram os principais mecanismos utilizados pelo Santo Ofício para atingir o Brasil.

No final do século XVI, a Inquisição passou a enviar visitações à América portuguesa. Realizada pelo Licenciado Heitor Furtado de Mendonça entre 1591 e 1595, a primeira delas atingiu as capitanias da Bahia, Pernambuco e Paraíba. A Bahia seria novamente visitada entre 1618 e 1621 por Marcos Teixeira. Ainda na década de 1620, embora a documentação seja mais escassa, temos notícia duma outra Visitação que percorreu o Brasil, passando pelo Espírito Santo, Rio de Janeiro, Santos e São Paulo. No caso desta última, apesar de várias denúncias recebidas, apenas uma pessoa foi processada, Izabel Mendes, acusada de Judaísmo. ${ }^{3}$

As visitações ocorridas no Brasil durante o final do século XVI e início do XVII integram um contexto maior em que outras áreas do lado atlântico do Império foram também visitadas: Açores em 1575-1576, Açores e Madeira em 1591-1593 e 1618-1619, Angola em 1561-1562, 1589-1591 e 1596-1598. Essa estratégia de ação do Santo Ofício através das visitações foi utilizada sobretudo no século XVI e na primeira metade da centúria seguinte. A partir desse período as visitações entram em decadência. Sobre essa matéria, concordamos com Bethencourt, para quem a Visitação do Santo Ofício ao Estado do Grão-Pará, ocorrida entre 1763-1769, foi “excepcional sob todos os pontos de vista". ${ }^{4}$

Concomitante ao declínio das visitações, notamos um crescimento do número das habilitações de agentes inquisitoriais expedidas pelo Santo Ofício, cujo ápice foi atingido no século XVIII. Isso significa que a Inquisição foi mudando sua estratégia, passando a se apoiar cada vez mais na rede de agen- 
tes próprios composta principalmente por comissários, notários, qualificadores e familiares. Essa expansão da hierarquia inquisitorial pode ser observada na Tabela 1, cujos dados excluem os familiares - dos quais não trataremos por ora -, mas adiantamos que a difusão de sua rede seguiu a mesma tendência geral verificada para os outros agentes.

Tabela 1 - Expansão dos quadros burocráticos inquisitoriais

\begin{tabular}{c|c|c|c|c|c}
\hline Período & Comissários & Notários & $\begin{array}{c}\text { Deputados e } \\
\text { Inquisidores }\end{array}$ & Qualificadores & $\begin{array}{c}\text { Não } \\
\text { especificados }\end{array}$ \\
\hline $1580-1620$ & 132 & - & 38 & 47 & - \\
$1621-1670$ & 297 & - & 117 & 110 & - \\
$1671-1720$ & 637 & 14 & 94 & 287 & 33 \\
$1721-1770$ & 1.011 & 404 & 119 & 419 & 20 \\
$1771-1820$ & 484 & 189 & 62 & 62 & 1 \\
\hline
\end{tabular}

Fonte: TORRES, José Veiga. Da repressão à promoção social: a Inquisição como instância legitimadora da promoção social da burguesia mercantil. Revista Crítica de Ciências Sociais, v.40, out. 1994, p.105-135. p.130.

A atuação do Santo Ofício em Minas Gerais, cujo povoamento e colonização ocorreu no Setecentos, se insere nesse contexto de desaparecimento há muito tempo das visitações inquisitoriais e crescimento da rede de agentes do Santo Ofício. A engrenagem inquisitorial que permitiu a atuação do Tribunal de Lisboa na Capitania era composta por três grupos de agentes: os comissários, os notários e os familiares. Além dessa rede - e integrada a ela - foi relevante a complexa articulação ocorrida entre as instâncias da justiça eclesiástica existentes na Capitania e o Santo Ofício.

A ocupação de cada um dos postos da hierarquia inquisitorial exigia requisitos específicos, e cada um dos grupos de agentes possuía um perfil. Os familiares, por exemplo, não precisavam ser eclesiásticos, bastava terem limpeza de sangue, saber ler e escrever e ter algum recurso. Além disso, o número de componentes das redes variava de acordo com as funções de cada cargo. Levantamentos realizados nos livros de provisões da Inquisição de Lisboa revelam que a capitania de Minas, ao longo do século XVIII, contou com 457 familiares, 22 comissários e 8 notários. ${ }^{5}$ Nos limites deste artigo, tais variações e especificidades impedem a realização de um estudo sistemático para cada um desses grupos de oficiais do Santo Ofício. Portanto, o enfoque deste trabalho recairá sobre os comissários presentes em Minas: seu recrutamento, perfil 
e atuação. Essas problemáticas serão desenvolvidas, em diferentes momentos da análise, pelo viés da inserção dos comissários nas estruturas eclesiásticas locais.

O recorte adotado neste texto se justifica também pela posição chave que os comissários desempenhavam na Colônia. Na capitania do ouro, atuando de diversas maneiras, esses agentes constituíram um mecanismo fundamental para o funcionamento da engrenagem inquisitorial, pois eles eram a autoridade inquisitorial máxima na Colônia e acabavam desempenhando funções catalisadoras nas regiões em que atuavam. Na hierarquia dos oficiais da Inquisição, os comissários se subordinavam diretamente aos Inquisidores de Lisboa.

Esclarecer as questões em xeque neste artigo é um passo importante para o conhecimento do aspecto institucional da atuação do Santo Ofício em Minas Gerais, tema ainda carente de estudos sistemáticos na historiografia brasileira.

\section{ESTRUTURA ECLESIÁSTICA E INQUISIÇÃO: O PERFIL E A ATUAÇÃO DOS COMISSÁRIOS EM MINAS}

Além das qualidades exigidas para todos os postos inquisitoriais - ser cristão-velho, sem ascendente condenado pela Inquisição, ter bons costumes -, a ocupação do cargo de comissário tinha como requisitos que os candidatos fossem "pessoas eclesiásticas, de prudência e virtude conhecida, e achandose letrados serão preferidos". Era dada preferência aos que fossem letrados. As principais funções desses agentes eram ouvir testemunhas nos processos de réus, realizar contraditas, coletar depoimentos nos expedientes de habilitação de agentes inquisitoriais, fazer prisões e organizar a condução dos presos e vigiar os condenados que cumprissem pena de degredo nas áreas de sua atuação. Como os comissários não atuavam na sede dos tribunais inquisitoriais e acumulavam o cargo com outras atividades desempenhadas na qualidade de eclesiásticos, eles integravam o grupo de agentes inquisitoriais que não recebiam um salário fixo da Inquisição: ganhavam seis tostões por dia de trabalho. ${ }^{6}$

No contexto de expansão de toda a hierarquia de agentes inquisitoriais mostrado na Tabela 1, a rede de comissários do Santo Ofício começou a ganhar fôlego nas últimas décadas do século XVII. O seu ápice foi atingido no século XVIII, quando alcançou a cifra de 1.011 habilitações no período que 
vai de 1721 a 1770, um aumento de 374 agentes em relação aos cinquenta anos anteriores (quando eram 637).

De maneira geral, pouco se sabe sobre a rede de comissários presentes e atuantes na América portuguesa. Luiz Mott tem sido pioneiro ao chamar atenção para a necessidade de se estudar esse aspecto da ação inquisitorial ocorrida na Colônia. ${ }^{7}$

Até o momento, contamos com dados de alcance regional sobre as redes de comissários. Em um levantamento incompleto, Sônia Siqueira encontrou 80 comissários para as capitanias de Bahia e Pernambuco, distribuídos da seguinte forma: 8 no século XVII, sendo 6 para a Bahia e 2 para Pernambuco; 67 no século XVIII, sendo 36 para a primeira e 31 para a última, e 5 no século XIX, dois deles para a Bahia e 3 para Pernambuco. Já Wadsworth, num estudo exaustivo para Pernambuco, entre 1611 e 1820, encontrou 68 comissários, além de 62 notários e 14 qualificadores. ${ }^{8}$

No caso da Capitania de Minas Gerais, Wadsworth cita a existência de 13 comissários. Porém, pesquisando em diversas fontes, sobretudo nos Livros dos Termos de Provisões e Juramentos da Inquisição de Lisboa, encontramos 23, cuja distribuição por comarcas era a seguinte: Vila Rica - que abrigava Mariana, a sede do Bispado -, 13; Rio das Velhas, 5; Rio das Mortes, 3 e, por último, Serro do Frio, 1. A evolução dessa rede por período, comarca e freguesia pode ser observada no Quadro 1.

Para além do desenvolvimento econômico e social da região, a montagem da rede de comissários em Minas está ligada à estruturação da instituição eclesiástica no território da Capitania pós-1745-1748. Essa constatação pode ser explicada se considerarmos que um dos requisitos para a ocupação do cargo de comissário era o candidato ser eclesiástico e, nessa qualidade, geralmente possuir algum benefício (até onde sabemos, 14 dos comissários da Capitania tinham benefício). Dos 22 habilitados, 16 tiveram suas patentes expedidas depois da criação do Bispado de Mariana - ocorrida em 1745-1748. Esse evento atraiu para Minas um clero mais bem formado, mais ambicioso por subir na carreira e assentado em benefícios eclesiásticos.

No território minerador, as Ordens Regulares foram proibidas de se estabelecerem oficialmente, sendo alvo de uma política da Coroa que cerceava a sua presença e atuação na região. ${ }^{9}$ Dada a fraca presença oficial dos clérigos regulares em Minas - no sentido de "sedentarizados" institucionalmente, de modo que a Inquisição pudesse neles se apoiar —, os comissários só poderiam ser recrutados entre os membros da hierarquia eclesiástica secular. 
Quadro 1 - Habilitação de comissários do Santo Ofício em Minas (século XVIII)

\begin{tabular}{|c|c|c|}
\hline Ano & Comarca (secular) & Freguesia \\
\hline 1724 & Vila Rica & Mariana \\
\hline 1726 & Rio das Velhas & Morro Grande \\
\hline 1729 & Rio das Velhas & Rio das Pedras \\
\hline 1730 & Vila Rica & Vila Rica \\
\hline 1733 & Rio das Velhas & Raposos \\
\hline 1733 & Vila Rica & Mariana \\
\hline 1747 & Vila Rica & Mariana \\
\hline 1748 & Vila Rica & Vila Rica \\
\hline 1749 & Rio das Velhas & Sabará \\
\hline 1749 & Vila Rica & Mariana \\
\hline 1752 & Rio das Mortes & Piedade da Borda do Campo \\
\hline 1752 & Rio das Velhas & Vila Nova da Rainha \\
\hline 1754 & Vila Rica & Sumidouro \\
\hline 1758 & Vila Rica & Mariana \\
\hline 1758 & Serro Frio & Vila do Príncipe \\
\hline 1760 & Rio das Mortes & São João Del Rei \\
\hline 1763 & Vila Rica & Furquim \\
\hline 1765 & Vila Rica & Vila Rica \\
\hline 1766 & Vila Rica & Mariana \\
\hline 1766 & Rio das Mortes & Prados \\
\hline 1769 & Vila Rica & Vila Rica \\
\hline 1798 & Vila Rica & Mariana \\
\hline
\end{tabular}

Fonte: IANTT, HSO; IL, Provisões de nomeação e termos de juramentos, liv. 104-123. Este quadro leva em conta os dados referentes ao momento de conclusão da habilitação dos comissários.

Com exceção de Minas, nas outras regiões sob sua jurisdição a Inquisição eventualmente se apoiava no clero das Ordens Regulares, sobretudo nos padres da Companhia de Jesus. Esse fato pode ser facilmente verificado se 
observarmos os destinatários das correspondências do Santo Ofício dirigidas à Colônia. No Rio de Janeiro, por exemplo, várias comissões eram enviadas ao comissário Estevão Gandolfe, membro da Companhia de Jesus. ${ }^{10}$ Em São Paulo, os reitores do Colégio dos Jesuítas também se faziam de comissários da Inquisição. Eles eram encarregados de executar diligências mesmo que não tivessem se habilitado formalmente como agentes inquisitoriais. ${ }^{11}$

Segundo Feitler, no Nordeste, entre 1702 e 1729, os jesuítas foram os correspondentes privilegiados dos inquisidores nas regiões de Pernambuco e Paraíba, apesar de o Tribunal já contar com a participação de agentes próprios na ação inquisitorial que ali se desenrolava. Essa relação já vinha desde o período da Sé Vacante de Olinda (1693-1697), quando o reitor do Colégio dos Jesuítas, Felipe Coelho, era o principal destinatário das correspondências que a Inquisição endereçava àquela região. ${ }^{12}$

$\mathrm{Na}$ África, a partir do século XVII, Filipa Ribeiro da Silva encontrou colaboradores da Inquisição entre os franciscanos nas regiões de Cabo Verde e da Guiné e, no caso de São Tomé e Príncipe, capuchinhos italianos e agostinhos descalços. ${ }^{13}$ Tanto na África Ocidental como na América portuguesa mesmo que não fosse de forma prioritária e variasse de acordo com o contexto - havia uma relação entre os regulares, a estrutura eclesiástica e o Santo Ofício.

Em Minas não havia essa relação, por isso a criação do Bispado e a decorrente atração de um clero mais bem qualificado para a Capitania teve influência no recrutamento da rede de comissários e na ação inquisitorial ocorrida na região.

Ao analisar a inserção dos comissários no espaço eclesiástico da capitania mineradora, notamos que eles se situavam numa hierarquia, tanto no momento da habilitação como - nos casos para os quais dispomos de informações - nos cargos que iam ocupando ao longo de suas carreiras. Alguns acumulam postos dentro do Cabido, outros atingem a colocação máxima do Juízo Eclesiástico - vigário-geral —, e havia também os que não passavam de simples vigários ou párocos. 


\section{Quadro 2 - Cargos ocupados pelos comissários na esfera eclesiástica (por ano de habilitação)}

\begin{tabular}{|c|c|c|c|}
\hline Nome & $\begin{array}{c}\text { Ano de } \\
\text { habilitação }\end{array}$ & $\begin{array}{c}\text { Formação } \\
\text { universitária }\end{array}$ & $\begin{array}{c}\text { Cargos ocupados } \\
\text { no momento e depois } \\
\text { da habilitação }\end{array}$ \\
\hline $\begin{array}{l}\text { Francisco Ribeiro } \\
\text { Barbas }\end{array}$ & 1724 & & $\begin{array}{l}\text { Vigário da Vara de Ribeirão } \\
\text { do Carmo }\end{array}$ \\
\hline José Pinto da Mota & 1726 & & Vigário Encomendado \\
\hline João Soares Brandão & 1729 & & Vigário Colado \\
\hline Manuel Freire Batalha & 1730 & $\begin{array}{l}\text { Bacharel em } \\
\text { Cânones }\end{array}$ & $\begin{array}{l}\text { Visitador Episcopal, } \\
\text { Mestre-Escola no RJ (1742), } \\
\text { Deão no RJ (1756) }\end{array}$ \\
\hline José Matias de Gouveia & 1733 & & Vigário Colado \\
\hline Jose Simões & 1733 & & Vigário Colado \\
\hline $\begin{array}{l}\text { Geraldo José de } \\
\text { Abranches }\end{array}$ & 1747 & $\begin{array}{l}\text { Bacharel em } \\
\text { Cânones }\end{array}$ & $\begin{array}{l}\text { Vigário-geral, Provisor, } \\
\text { comissário geral da bula } \\
\text { da Santa Cruzada }\end{array}$ \\
\hline Felix Simões de Paiva & 1748 & $\begin{array}{l}\text { Bacharel em } \\
\text { Cânones }\end{array}$ & $\begin{array}{l}\text { Comissário da Bula da Cruzada, } \\
\text { Vigário da Vara de Vila Rica, } \\
\text { Visitador Episcopal }\end{array}$ \\
\hline Inácio Correia de Sá & 1749 & $\begin{array}{l}\text { Bacharel em } \\
\text { Cânones }\end{array}$ & $\begin{array}{l}\text { Vigário da Vara de Vila Rica, } \\
\text { Procurador e Governador do } \\
\text { Bispado, Vigário Capitular, } \\
\text { Vigário-geral, cônego Doutoral, } \\
\text { Tesoureiro-mor }\end{array}$ \\
\hline $\begin{array}{l}\text { Lourenço José de } \\
\text { Queiroz Coimbra }\end{array}$ & 1749 & $\begin{array}{l}\text { Bacharel em } \\
\text { Cânones }\end{array}$ & $\begin{array}{l}\text { Vigário Colado, Procurador e } \\
\text { Governador do Bispado, } \\
\text { Visitador Episcopal }\end{array}$ \\
\hline Feliciano Pita de Castro & 1752 & & Vigário colado \\
\hline Henrique Pereira & 1752 & $\begin{array}{l}\text { Bacharel em } \\
\text { Cânones }\end{array}$ & Vigário \\
\hline Manoel Nunes de Souza & 1754 & $\begin{array}{l}\text { Bacharel em } \\
\text { Cânones }\end{array}$ & Vigário \\
\hline $\begin{array}{l}\text { Manoel Cardoso Frasão } \\
\text { Castelo Branco }\end{array}$ & 1758 & $\begin{array}{l}\text { Bacharel em } \\
\text { Cânones }\end{array}$ & $\begin{array}{l}\text { Vigário da Vara do Serro Frio, } \\
\text { Vigário da Vara de Vila Rica, } \\
\text { Arcipreste e Vigário-geral }\end{array}$ \\
\hline
\end{tabular}




\begin{tabular}{|c|c|c|c|}
\hline $\begin{array}{l}\text { Teodoro Ferreira } \\
\text { Jacome }\end{array}$ & 1758 & $\begin{array}{l}\text { Bacharel em } \\
\text { Cânones }\end{array}$ & $\begin{array}{l}\text { Cônego e Tesoureiro-mor, } \\
\text { Vigário-geral, Governador do } \\
\text { Bispado, Reitor do Seminário } \\
\text { de Mariana, Visitador Episcopal }\end{array}$ \\
\hline Jose Sobral e Souza & 1760 & $\begin{array}{l}\text { Bacharel em } \\
\text { Cânones }\end{array}$ & $\begin{array}{l}\text { Vigário da Vara de São João } \\
\text { Del Rei }\end{array}$ \\
\hline $\begin{array}{l}\text { João de Sá e } \\
\text { Vasconcelos }\end{array}$ & 1763 & & Vigário Colado \\
\hline Nicolau Gomes Xavier & 1765 & & Vigário \\
\hline João Roiz Cordeiro & 1766 & $\begin{array}{l}\text { Bacharel em } \\
\text { Cânones }\end{array}$ & Cônego Magistral \\
\hline $\begin{array}{l}\text { Manoel Martins de } \\
\text { Carvalho }\end{array}$ & 1766 & & Vigário Colado \\
\hline $\begin{array}{l}\text { João de Oliveira } \\
\text { Guimarães }\end{array}$ & 1769 & $\begin{array}{l}\text { Bacharel em } \\
\text { Cânones }\end{array}$ & Vigário Colado \\
\hline $\begin{array}{l}\text { Manuel Arcúsio } \\
\text { Nunam Pereira }\end{array}$ & 1798 & & Cônego prebendado \\
\hline
\end{tabular}

Fonte: IANTT, HSO; IANTT, IL, Provisões de nomeação e termos de juramentos (livros 104123). Sobre os cargos na hierarquia, a informação consta em:TRINDADE, Raimundo. Arquidiocese de Mariana: subsídios para sua História. Belo Horizonte: Imprensa Oficial, 1953. v.I; CHIZOTI, Geraldo. O Cabido de Mariana (1747-1820). Franca, 1984. Dissertação (Mestrado) - Unesp.

A relação entre o desenvolvimento da rede de comissários e a criação do Bispado de Mariana pode ser constatada também com base na análise dos registros das correspondências enviadas pela Inquisição às Minas - que abarcam todo o século XVIII, exceto a década de 1770. Quando analisamos a data de envio das diligências, notamos que antes de 1745-1748 quase não houve comissão encaminhada aos comissários e aos outros clérigos residentes na Capitania. ${ }^{14}$ Do total de 122 registros, apenas em 14 encontramos correspondências enviadas para a Capitania antes da entrada de Dom Frei Manuel da Cruz na Sé de Mariana.

Quanto aos destinatários das correspondências, a análise revela que a tendência era a Inquisição dar prioridade aos comissários de melhor formação - geralmente preferindo os bacharéis em cânones -, que ocupavam os postos mais elevados na hierarquia eclesiástica da Capitania. No cômputo geral de 122 registros de correspondências enviadas às Minas, abarcando o século XVIII, os comissários foram os destinatários de 102 delas. Destacando esse grupo, observamos que Inácio Correia de Sá - bacharel em cânones que 
ocupou, ao longo de sua carreira, o posto de vigário da vara de Vila Rica, cônego da Sé de Mariana, vigário-geral e tesoureiro-mor - foi o que mais contou com a confiança dos inquisidores, pois a ele foram encaminhadas 25 diligências, entre 1754 e 1768.

Além dos cargos já citados, Inácio Correia de Sá exerceu ainda um papel importante quando tomou posse como procurador do novo Bispo de Mariana, Dom Frei Domingos da Encarnação Pontevel, em 29 de agosto de 1779. O comissário governou o Bispado até 25 de fevereiro de 1780, data em que o prelado - de quem ele era procurador - chegou para tomar posse na Sé de Mariana. ${ }^{15} \mathrm{O}$ fato de Inácio Correia de Sá ter uma boa formação acadêmica - bacharel em cânones - e ter ocupado cargos chave na hierarquia eclesiástica do Bispado teve influência direta no número de comissões que a Inquisição lhe enviou.

Além da importância dada pela Inquisição aos indivíduos que ocupavam o topo da hierarquia eclesiástica local, certamente havia um interesse por parte do alto clero da Capitania em servir à Inquisição. Ser agente do Santo Ofício era uma forma de se obter prestígio e, além disso, poder ascender na própria hierarquia clerical, ou até mesmo na inquisitorial. No caso daqueles que tinham ambição de ascender nos quadros da Igreja, ter serviços prestados ao Santo Ofício no curriculum poderia ser um elemento importante para a concretização de seus anseios.

O segundo comissário de Minas para quem mais os inquisidores encaminharam diligências (16, entre 1751 e 1781) foi Lourenço José de Queiroz Coimbra que, assim como Inácio Correia de Sá, era bacharel em cânones. De origem minhota, veio para o Rio de Janeiro em 1734 e, com apenas 23 anos, D. Frei de Guadalupe o fez vigário colado de Sabará. Em 1748, no ano da instalação do Bispado de Mariana, Coimbra exerceu papel fundamental ao governar interinamente a nova Diocese por nove meses, preparando a chegada de Dom Frei Manuel da Cruz. Segundo Raimundo Trindade, Coimbra partira de Sabará em 25 de fevereiro de 1748 e chegou a Mariana no dia 27, "seguido de mais de mil cavaleiros, do ouvidor de sua comarca e de numeroso Clero, gente luzida que, vestida de gala, em vistosa tropa, o acompanhou à Cidade”. Ao regressar para Sabará, de onde havia saído como vigário colado, voltava, nomeado pelo novo bispo, como vigário da vara - ocupação geralmente re- 
servada a clérigos bacharéis em cânones - daquela Comarca eclesiástica, onde residiria até sua morte. ${ }^{16}$

Além dos dois comissários referidos, destinatários de boa parte das correspondências dirigidas às Minas, outros 14 - num universo de 22 - foram incumbidos de realizar diligências para a Inquisição de Lisboa. Manuel Freire Batalha - bacharel em cânones e com experiência de visitador episcopal -, entre 1732 e 1741, foi encarregado de 12 diligências. O bacharel em cânones Félix Simões de Paiva - que tinha experiência precedente no cargo de provisor e vigário-geral em Mazagão, vigário da vara em Vila Rica e visitador episcopal -, foi responsável, entre 1748 e 1758, por 12 diligências. Teodoro Ferreira Jacome, também bacharel em cânones, entre 1760 e 1764, foi responsável por 6 comissões. Este, além dos cargos no cabido de Mariana, tinha sido visitador episcopal e promotor eclesiástico da vigaria da vara de Vila Rica. O bacharel em cânones José Sobral, entre 1761 e 1766, ficou com 6 diligências; Geraldo José de Abranches, entre 1749 e 1753, recebeu 6 comissões; Nicolau Gomes Xavier, entre 1795 e 1801, ficou com 5; Feliciano Pita de Castro, entre 1754 e 1764, 5. Quanto a outro grupo de 5 comissários, geralmente com baixa formação e sem cargos importantes, foi encaminhada apenas 1 correspondência para cada um.

O destino mais frequente das correspondências, cujo conteúdo se referia, em geral, à execução de diligências, era a sede do Bispado, seguida da Comarca de Sabará, Vila Rica e São João Del Rei. Se em Mariana as diligências eram encaminhadas sobretudo aos comissários com postos no Cabido ou na justiça eclesiástica, fora da sede episcopal era dada preferência aos comissários que ocupavam os postos de vigário da vara, caso, por exemplo, de Sabará e São João Del Rei.

Outros dois "assuntos" eram responsáveis pelo fluxo das correspondências entre a Inquisição e as autoridades eclesiásticas de Minas. Primeiramente, temos a demanda por habilitação de familiares do Santo Ofício e, depois, o funcionamento da engrenagem que havia gerado denúncias e sumários cujos desdobramentos resultaram em investigações e mandados diversos para apuração dos casos. Veja-se o universo de 110 registros de correspondências referentes a Minas, na Tabela 2. 
Aldair Carlos Rodrigues

\begin{tabular}{|c|c|c|c|c|c|c|c|c|c|}
\hline $\overrightarrow{\tilde{\Xi}}$ & $\stackrel{\infty}{\sim}$ & 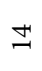 & \& & 요 & 0 & $\sim$ & $\curvearrowright$ & $\neg$ & \\
\hline 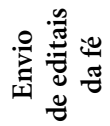 & - & 0 & 0 & 0 & 0 & 0 & 0 & 0 & - \\
\hline 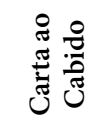 & 0 & 0 & 0 & $\sim$ & 0 & 0 & 0 & 0 & $\sim$ \\
\hline 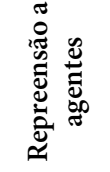 & 0 & 0 & - & $m$ & 0 & 0 & 0 & 0 & 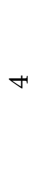 \\
\hline 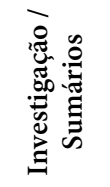 & $H$ & $m$ & 으 & 으 & 0 & $\sim$ & 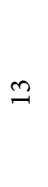 & 0 & $\mathcal{F}$ \\
\hline 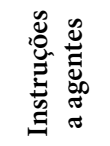 & 0 & 0 & - & 0 & 0 & 0 & 0 & 0 & - \\
\hline 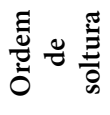 & 0 & 0 & - & $N$ & 0 & 0 & - & 0 & $r$ \\
\hline בُ & $H$ & $m$ & $\Lambda$ & - & 0 & 0 & $\sim$ & $\neg$ & $\stackrel{\infty}{-}$ \\
\hline 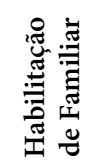 & $a$ & $\infty$ & $\stackrel{\mathscr{2}}{\sim}$ & ๗ె & 0 & 0 & $m$ & 0 & $\hat{\wedge}$ \\
\hline 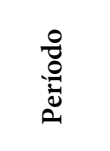 & 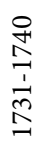 & 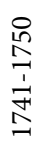 & $\begin{array}{l}8 \\
\stackrel{8}{1} \\
\frac{1}{10} \\
1\end{array}$ & $\begin{array}{l}\stackrel{2}{1} \\
\frac{1}{1} \\
\frac{1}{1}\end{array}$ & $\begin{array}{l}\infty \\
\stackrel{2}{N} \\
\frac{1}{1} \\
\text { N } \\
=\end{array}$ & $\begin{array}{l}\Re \\
2 \\
\frac{1}{1} \\
\infty \\
1\end{array}$ & 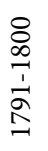 & $\begin{array}{l}0 \\
\infty \\
+1 \\
1 \\
0 \\
0\end{array}$ & 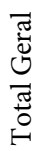 \\
\hline
\end{tabular}


Um importante dado a ser observado na Tabela 2 é a coincidência entre as diligências tocantes a "habilitação de familiares" e a "investigação/sumários" concentrados entre as décadas de 1750 e 1770. José Veiga Torres afirma que a expansão do quadro de comissários, bem como de outros cargos da Inquisição portuguesa, visava acompanhar a demanda por habilitações ao cargo de familiar do Santo Ofício. Os comissários exerceriam atividades relacionadas à burocracia da habilitação, sobretudo os interrogatórios. Essa constatação corroboraria a tese do autor de que a Inquisição deixou a repressão para trabalhar sobretudo na promoção social a partir das últimas décadas do século XVII.

No tocante à repressão, o autor se baseou na queda do número de sentenciados, e, quanto à promoção social, ancorou-se no extraordinário aumento do número de Familiaturas. No caso de Minas, a evolução da rede de comissários acompanhou, de modo geral, a tendência observada para Portugal continental e o Império. A maior parte dos registros de correspondências endereçadas à Capitania é relativa à habilitação de familiares, portanto, a formação da rede de comissários acompanhou a evolução da rede de familiares. Além disso, o número de diligências referentes a mandados de prisão, sumários, contraditas, investigações e inquéritos, de modo geral, concentra-se também entre as décadas de 1750 e 1770.

Portanto, no caso de Minas, os comissários não estavam apenas atuando nas habilitações ao cargo de familiar, embora essa fosse a atividade que mais exercessem em nome da Inquisição. O período em que os comissários da Capitania mais se ocuparam da habilitação de familiares do Santo Ofício foi também aquele em que mais exerceram atividades relativas à ação repressiva do Tribunal.

\section{COMISSÁRIOS E AÇÃO INQUISITORIAL: o caso de Manuel Freire Batalha}

As primeiras informações disponíveis sobre a atuação dos comissários em Minas datam da década de 1730. Antes desse período, conforme vimos na Tabela 2, nenhuma correspondência endereçada à Capitania foi encontrada no Registro Geral do Expediente. Nos Cadernos do Promotor - importante conjunto documental que funcionava como um depositário de denúncias e sumários de uma grande variedade de delitos - , as informações acerca da atuação inquisitorial na Capitania mineradora também são muito escassas para os vinte primeiros anos do Setecentos. 
Na década de 1730, encontramos Manuel Freire Batalha, cuja residência ficava na Cabeça da Capitania, atuando como o principal comissário de Minas. Era bacharel formado em cânones e se habilitou ao cargo de agente da Inquisição em 1730, quando atuava como pároco em Vila Rica. Batalha era bastante ativo na região, tanto que foi visitador diocesano um ano antes de sua habilitação e também em 1730, quando já era comissário, tendo percorrido várias freguesias da Comarca do Rio das Mortes e de Vila Rica. ${ }^{17}$

Manuel Freire Batalha foi um esteio importante para a ação inquisitorial nas Minas durante a década de 1730, período em que os habitantes da Capitania processados pela Inquisição, cristãos-novos em sua maioria, receberam duras penas. ${ }^{18}$ Nos 14 registros das correspondências enviadas pela Inquisição de Lisboa às Minas antes da criação do Bispado de Mariana consta que Batalha foi o destinatário de 12 delas. ${ }^{19}$ José Simões, comissário e vigário da vara de Mariana, foi incumbido das outras duas diligências.

A primeira referência a Minas no registro das correspondências aparece no ano de 1732 em carta enviada ao comissário do Rio, Lourenço de Valadares Vieira. Nesta, ordenava-se o envio do retrato de Miguel de Mendonça Valladolid, condenado à pena capital pela Inquisição, para que fosse "posto na freguesia onde era morador sobre a portada da Igreja da parte de dentro". Embora não tenha sido explicitado o destinatário da diligência, tudo indica que ela fora enviada a Manuel Freire Batalha. ${ }^{20}$

Em setembro de 1732 encontramos outra correspondência referente a Minas, desta vez especificando que era destinada ao "comissário das Minas Gerais ou alguma pessoa de confiança". Na diligência havia três mandados de prisão, com sequestro de bens, referentes a Manoel Gomes de Carvalho, Manoel de Matos Dias e Manoel da Costa Ribeiro. Além disso, trazia o retrato de Diogo Correa do Vale, condenado à pena capital pela Inquisição, para que fosse colocado "na Igreja principal das Minas de Ouro Preto em cima da porta da parte de dentro". Junto da comissão, iam também os interrogatórios da habilitação de João Moreira de Carvalho ao cargo de familiar do Santo Ofício. ${ }^{21}$ É muito provável que Batalha tenha sido o responsável por essas diligências, já que era o único comissário residente em Vila Rica naquele momento.

Em 30 de outubro de 1733, outra correspondência com destino às Minas foi registrada, ficando agora explícito que o destinatário era o comissário Manuel Freire Batalha. Nesta, eram remetidos dez mandados de prisão, além de comissão para ratificar testemunhas do sumário que tinha sido enviado por aquele comissário ao Tribunal de Lisboa contra João de Moraes Leitão, acusa- 
do de ter confessado sem ordens. Novamente, eram enviadas diligências relacionadas a habilitações de familiares. ${ }^{22}$

Em resposta a essa comissão, Batalha escreveu à Inquisição, no ano seguinte, uma longa carta de oito fólios, na qual oferece um panorama geral da ação inquisitorial nas Minas até aquele momento, terras onde, em sua opinião, "soava de mui longe a voz do Santo Ofício". ${ }^{23}$

Além da carta de seu punho, o comissário remeteu em anexo uma lista elaborada pelo tesoureiro do Fisco Real, contendo o nome de 16 réus das Minas, quase todos cristãos-novos, que haviam sido presos e tiveram seus bens confiscados, cujo valor líquido total somava 21:892\$775 (21 contos, $892 \mathrm{mil} \mathrm{e}$ 775 réis), uma verdadeira fortuna.

$\mathrm{Na}$ referida carta, além de tratar de problemas relacionados ao juízo do fisco e aos familiares do Santo Ofício, o comissário dava conta de prisões ordenadas pela Inquisição e réus a serem enviados ao Santo Ofício, como, por exemplo, Ana do Vale, Helena do Vale e João de Morais Leitão. Em um dos inúmeros parágrafos, o comissário especificamente reclamava de sua baixa remuneração diante dos altos custos dos mantimentos e da vida nas Minas, argumentando a respeito:

só por exemplo (por não irmos mais longe; pois não o estamos ainda da quaresma) basta dizer a V Em.a que sendo os regalos dela um pouco de bacalhau, que mais ofende o olfato, do que lisonjeia o paladar custam tanto duas libras só dele, como pode custar uma arroba da mais singular da nossa Corte, um frasco de azeite dezoito tostões, um de vinagre o mesmo, um de vinho outro tanto, um alqueire de milho doze, ou quinze tostões, quando barato, que custa seis vinténs dentro em Lisboa, um de farinha, que é o pão comum, dezoito e vinte e mais, um pão como o de dez[r] do Reino oito vinténs, umas casas, e não das de melhores cômodos duas, três e quatro moedas cada mês...

Depois da reclamação, o comissário informava aos inquisidores sobre os seus esforços para executar os vários mandados da Inquisição que paravam em suas mãos. Sobre isso, ele escrevia: "estou conservando correspondências por todos estes sertões com as pessoas em que considero inteligência para qualquer emprego". Uma das pessoas em questão era o superintendente das Minas Novas, região na qual se encontravam alguns refugiados da Inquisição. Além do superintendente, Batalha informou que mantinha correspondência com os "Goiazes", onde alguns acusados haviam se refugiado.

Em sua carta, Batalha relatava aos inquisidores a dificuldade de se cum- 
prirem todas as diligências dada a dispersão dos réus pelas Minas, afirmando que "outros se acham mortos e outros tão penetrados em os sertões que é quase impraticável dar lhe alcance”.

Ao final da carta, o comissário aborda a questão da via pela qual as correspondências e notícias sobre a Inquisição chegavam à capitania mineradora. Ele pedia ao Tribunal que as cartas e mandados de prisão passassem a ser enviados por meio das bolsas da Secretaria de Estado com os "pregos de El Rei, que vêm para o governador das Minas, porque estes os trazem de fora da barra os capitães do Rio, que já tem próprio a espera e são os primeiros que partem".

$\mathrm{O}$ argumento para que as correspondências viessem por tal via era que, do contrário, chegavam às Minas 10 ou 12 dias depois de chegarem as primeiras cartas vindas na frota recém-aportada no Rio de Janeiro. Estas, que chegavam primeiro, traziam as listas e relatos dos autos de fé "ou notícias, que põem de acordo aos cúmplices para se retirarem”. Chegando, então, as notícias da possibilidade da perseguição que o Santo Ofício lhes movia, os réus e acusados tinham mais tempo para fugir, já que as cartas da Inquisição ao comissário não eram as primeiras a chegar às Minas.

Foi o que aconteceu com o denunciado João Roiz Mesquita que, vindo do Serro um dia antes de as cartas chegarem às mãos de Manuel Freire Batalha, fugiu para o Rio de Janeiro "com bastante cabedal", segundo informava o comissário.

Apesar de termos localizado somente uma dessas correspondências de natureza excepcional e de caráter bastante pessoal, em que um comissário das Minas escreve ao Tribunal de Lisboa dando informações muito diversificadas e amplas, a mesma carta faz referência a diversas outras, indicando-nos que havia uma importante troca de correspondências entre a Inquisição e seus agentes.

Nesse exemplo do comissário Batalha notamos que do lado de lá do Atlântico vinham mandados para se fazerem diligências diversas, ordens de prisão, inquéritos, sequestros e confiscos de bens, listas de autos de fé e retratos de réus para serem pendurados nas igrejas das freguesias dos condenados. Da parte de cá, eram dadas informações ao Tribunal sobre o paradeiro dos perseguidos, o apoio das autoridades locais na perseguição dos réus, a relação do Santo Ofício com outras instituições nas Minas, as deficiências da máquina inquisitorial que funcionava na região e sugestões de melhoria.

Dando continuidade ao rastreamento da comunicação do comissário Batalha com a Inquisição de Lisboa, após quase uma década sem registro de 
correspondências dirigidas às Minas, encontramos uma carta, datada de 16 de janeiro de 1742. Através dela eram remetidos dois mandados de prisão contra Manoel Pinheiro de Oliveira e o padre Antônio Alves Pegas, além de uma comissão de investigação contra João de Lemos Saldanha, acusado de bigamia. Verifica-se, nesse ponto, o aumento do número de diligências relacionadas à habilitação de familiares. Na referida correspondência aparecem onze habilitandos cujos processos estavam em andamento. ${ }^{24}$

Mas Manuel Freire Batalha não se limitava a executar as ordens que vinham de Lisboa. Nos Cadernos do Promotor, podemos encontrar várias denúncias que foram feitas a ele e encaminhadas ao Santo Ofício, algumas vindas do Tejuco, freguesia distante de Vila Rica. Nessa documentação também encontramos o comissário Batalha realizando sumários e enviando-os para Portugal. Em 1742, por exemplo, foi responsável por realizar o sumário contra Domingos Morato, morador na freguesia de Catas Altas, Termo de Mariana, por ter feito desacatos a imagens. ${ }^{25}$

A partir daquele ano Batalha aparece na documentação inquisitorial atuando no Rio de Janeiro, e em 1748 o vigário Félix Simões de Paiva já ocupava seu posto de comissário em Vila Rica. O novo comissário recebeu diversas comissões referentes à habilitação de familiares do Santo Ofício e uma diligência contra o Frei Francisco de Santana. ${ }^{26}$

Até a criação do Bispado de Mariana, em 1745-1748, Batalha foi, sem dúvida, o comissário mais importante em Minas, e para ele convergia muito do que ocorria na Capitania, relacionado à Inquisição. Como vimos, até denúncias de freguesias longínquas lhes eram encaminhadas. Essa convergência era tributária do fato de esse comissário residir na sede administrativa da Capitania. As vias de comunicação, tanto para o que vinha do Reino como para o que vinha das diversas freguesias de Minas, concorriam para lá. Os locais de entreposto administrativo e entreposto inquisitorial se confundiam em Vila Rica.

Conforme verificamos detalhadamente, e não é demais frisá-lo, após a criação do Bispado de Mariana os comissários residentes na sede episcopal foram os que ganharam mais importância na perspectiva do Tribunal lisboeta no momento do envio de diligências a serem realizadas em Minas. Ocupando o lugar de cabeça eclesiástica da capitania, os assuntos relacionados à Inquisição agora passaram a convergir para Mariana e com mais intensidade. Uma das evidências desse fato é que Inácio Correia de Sá, como já foi dito, desde quando desempenhou a função de cônego do Cabido até quando ocupou o posto de vigário-geral, foi o comissário para quem a Inquisição mais enviou correspondências em Minas. 
Se nos registros das correspondências notamos mais os comissários recebendo diligências a serem feitas, nos Cadernos do Promotor podemos verificá-los atuando sobretudo nas denúncias. Nessa documentação, podemos conferir com mais clareza o grau de envolvimento da população das Minas com a máquina inquisitorial e a intermediação exercida pelos comissários.

Quando as pessoas, por diversos motivos, sentiam necessidade de fazer denúncias ao Tribunal do Santo Ofício, recorriam aos comissários. Esta foi a via mais utilizada por aqueles que foram à Inquisição com o objetivo de delatar. Luis da Costa Ataíde, por exemplo, procedeu dessa forma quando, em 1770, denunciou Ana Jorge por cometer desacatos com imagens católicas ao comissário de Mariana, João Roiz Cordeiro. Em 4 de abril de 1776, Rita de Souza, moradora de Nossa Senhora das Congonhas do Sabará, denunciou José, de nação nagô, ao comissário da freguesia de Raposos, Nicolau Gomes Xavier, por estar envolvido em práticas supersticiosas com suspeitas de feitiçaria. ${ }^{27}$

Não era só para denunciar a terceiros que as pessoas procuravam os comissários; também o faziam com o intuito de se autodenunciarem - para “descarga de suas consciências". Assim fez Manoel Coelho de Souza, em 1772, morador na freguesia de Antônio Pereira, quando se denunciou ao comissário João Roiz Cordeiro, por ter procurado benzeduras. Outro que se autodenunciou ao dito comissário foi Francisco, escravo Banguela, em 3 de maio de 1772. Em 1770, o comissário João Roiz Cordeiro também recebeu a autodenúncia da Crioula forra Catarina Maria de Oliveira, moradora da cidade de Mariana, por praticar superstições. ${ }^{28}$

Observando, então, esse aspecto das denúncias realizadas espontaneamente, os comissários foram o principal elo através do qual a população dava respostas à presença da Inquisição em Minas. Como ficou claro nestas páginas, a atuação desses agentes em Minas teve dois momentos: um antes e um depois da criação do Bispado de Mariana.

\section{NOTAS}

${ }^{1}$ Pesquisa realizada com bolsa da Fapesp (08/2004 a 07/2006); do Instituto Cultural Amílcar Martins (09/2006 a 02/2007); e, em Lisboa, entre fevereiro e abril de 2006, com bolsa da Cátedra Jaime Cortesão/Instituto Camões. Este trabalho foi desenvolvido no âmbito dos projetos Inquirir da honra: comissários do Santo Ofício e das Ordens Militares em Portugal, 1570-1773 (CIDEHUS, Univ. Évora, PTDC/HAH/64160/2006 - financiado pela FCT) e, no Brasil, dentro do projeto temático Dimensões do Império Português (Fapesp, 04/10367-0). 
${ }^{2}$ Cf. BETHENCOURT, Francisco. História das Inquisições: Portugal, Espanha e Itália séculos XV-XIX. São Paulo: Companhia das Letras, 2000. p.52. Sobre a tentativa de estabelecimento da Inquisição no Brasil, cf. NOVINSKY, Anita. Cristãos novos na Bahia. São Paulo: Perspectiva, 1992. 2.ed. p.108-109; SIQUEIRA, Sônia. A Inquisição portuguesa e a sociedade colonial. São Paulo: Ática, 1978. p.135-139; FEITLER, Bruno Guilherme. Inquisition, juifs et nouveaux-chrétiens au Brésil: le Nordeste, XVIIe et XVIIIe siècles. Louvain: Leuven University Press, 2003. p.64-69.

${ }^{3}$ ABREU, Capistrano de (Ed.). Primeira Visitação do Santo Ofício às partes do Brasil pelo licenciado Heitor Furtado de Mendonça. Confissões da Bahia, 1591-1592. São Paulo: Paulo Prado, 1922; ABREU, Capistrano (Org.). Primeira Visitação do Santo Ofício às partes do Brasil pelo licenciado Heitor Furtado de Mendonça. Denunciações da Bahia, 1591-1593. São Paulo: Paulo Prado, 1925; FRANÇA, Eduardo de Oliveira; SIQUEIRA, Sônia (Org.). Segunda Visitação do Santo Ofício às partes do Brasil pelo Inquisidor e Visitador Marcos Teixeira. Livro das Confissões e Ratificações da Bahia, 1618-1620, Anais do Museu Paulista, v.XVII, 1963; GARCIA, Rodolfo (Org.). Livro das denunciaç̃es que se fizeram na Visitação do Santo Ofício à cidade de Salvador da Bahia de Todos os Santos do estado do Brasil no ano de 1618. Anais da Biblioteca Nacional do Rio de Janeiro, v.49, 1927, p.75-198; . Primeira Visitação do Santo Ofício às partes do Brasil pelo Licenciado Heitor Furtado de Mendonça. Denunciações de Pernambuco, 1593-1595. São Paulo: Paulo Prado, 1929. Sobre a Visitação nas capitanias do Sul, consultar: GORENSTEIN, Lina. A terceira Visitação do Santo Oficio às partes do Brasil (século XVII). In: FEITLER, Bruno; LIMA, Lana Lage da Gama; VAINFAS, Ronaldo (Org.). A Inquisição em xeque: temas, controvérsias, estudos de caso. Rio de Janeiro: Eduerj, 2006. p.25-32.

${ }^{4}$ BETHENCOURT, Francisco. História das Inquisições..., 2000, p.215-217.

${ }^{5}$ Instituto dos Arquivos Nacionais/Torre do Tombo (doravante IANTT), Habilitações do Santo Ofício (doravante HSO); Inquisição de Lisboa (doravante IL), Provisões de nomeação e termos de juramentos, liv. 104-123.

${ }^{6}$ Todas as informações deste parágrafo em: Dos comissários e escrivães de seu cargo. Reg. 1640, Liv. I, Tit. XI. Regimentos do Santo Ofício (séculos XVI-XVII).

${ }^{7}$ MOTT, Luiz. A Inquisição em Sergipe. Aracaju: Score Artes Gráficas, 1987. p.60;

Um nome... em nome do Santo Ofício: o cônego João Calmon, comissário da Inquisição na Bahia setecentista. Universita, Salvador, n.37, jul.-set. 1986, p.15-32; A Inquisição no Maranhão. Revista Brasileira de História, São Paulo, n.28, v.15.

${ }^{8}$ SIQUEIRA, Sônia. A Inquisição portuguesa..., 1978, p.163; WADSWORTH, James. Agents of orthodoxy: inquisitional power and prestige in colonial Pernambuco, Brazil. Tese (Doutoramento) - University of Arizona, 2002. p.53.

${ }^{9}$ Sobre essa questão, cf. BOSCHI, Caio. "Como filhos de Israel no deserto?" (ou a expulsão dos eclesiásticos em Minas Gerais na $1^{\text {a }}$ metade do século XVIII). Vária História, Belo Horizonte, n.21, p.119-141; RESENDE, Renata. Entre a ambição e a salvação das almas: a atuação das Ordens Regulares em Minas Gerais (1694-1759). São Paulo, 2005. Dissertação 
(Mestrado) - FFLCH/USP. Renata Resende demonstra como o clero regular se fez presente em Minas, apesar da política da Coroa que impedia a sua instalação oficial na Capitania.

${ }^{10}$ IANTT, IL, Registro Geral do Expediente, Livro 20, fl. 249.

${ }^{11}$ Por exemplo, ver: IANTT, IL, Livro 20, Registro Geral do Expediente, fls. 252-252v.

${ }^{12}$ FEITLER, Bruno. Inquisition, juifs et nouveaux-chrétiens..., 2003. p.94-99.

${ }^{13}$ SILVA, Filipa Ribeiro da. A Inquisição na Guiné, nas Ilhas de Cabo Verde e São Tomé e Príncipe. Revista Lusófona de Ciência das Religióes, Lisboa, v.5, n.6, p.157-173, 2004. p.159.

${ }^{14}$ Todas as informações sobre as correspondências constam em: IANTT, IL, Registro Geral do Expediente, Livros 19-24.

${ }^{15}$ TRINDADE, Cônego Raimundo. Arquidiocese de Mariana: subsídios para sua história. Belo Horizonte: Imprensa Oficial, 1953. p.151.

${ }^{16}$ TRINDADE, Raimundo. Arquidiocese de Mariana..., 1953, p.78-82.

${ }^{17}$ BOSCHI, Caio César. As Visitas Diocesanas e a Inquisição na Colônia. Revista Brasileira de História, São Paulo, v.7, n.14, p.151-184. p.182; TRINDADE, Cônego Raimundo. Arquidiocese de Mariana..., 1953, p.60.

${ }^{18}$ Sobre os cristãos-novos em Minas, ver: FERNANDES, Neusa. A Inquisição em Minas Gerais no século XVIII. Rio de Janeiro: Eduerj, 2000; SALVADOR, José Gonçalves. Os cristãos-novos em Minas Gerais durante o ciclo do ouro. São Paulo: Pioneira, 1992.

${ }^{19}$ IANTT, IL, Registro Geral do Expediente, Livro 22. Agradeço a Bruno Feitler por ter cedido gentilmente a transcrição do registro das correspondências desse livro.

${ }^{20}$ IANTT, IL, Registro Geral do Expediente, Livro 22, fl. 29v.

${ }^{21}$ IANTT, IL, Registro Geral do Expediente, Livro 22, fl. 41.

${ }^{22}$ IANTT, IL, Registro Geral do Expediente, Livro 22, fl. 69v.

${ }^{23}$ Todas as informações referentes a essa carta, a partir das quais passamos a falar, em: IANTT, CGSO, Mç. 4, doc. 12.

${ }^{24}$ IANTT, IL, Registro Geral do Expediente, Livro 22, fl. 260.

${ }^{25}$ IANTT, IL, Cad. Promotor, Livro 295, fl 245; IANTT, IL, Cad. Promotor, Livro 295, fl. $40 \mathrm{v}$.

${ }^{26}$ IANTT, IL, Registro Geral do Expediente, Livro 22, fl. 380v.

${ }^{27}$ IANTT, IL, Cad. Promotor, Livro 318, fl. 234; IANTT, IL, Cad. Promotor, Livro 318, fl. 273.

${ }^{28}$ Respectivamente: IANTT, IL, Cad. Promotor, Livro 318, fl. 134. IANTT, IL, Cad. Promotor, Livro 318, fl. 273. Muitos casos de autodenúncia aos comissários podem ser encontrados nos Cadernos do Promotor. Para alguns exemplos, ver, no livro 381, as fls. 132, 156, 219, 221, 324, 325, 384; IANTT, IL, Cad. Promotor, Livro 318, fl. 273.

Artigo recebido em novembro de 2008. Aprovado em fevereiro de 2009. 